\title{
Molecular Detection of Epstein-Barr Virus, Human Herpes Virus 6, Cytomegalovirus, and Hepatitis B Virus in Patients with Multiple Sclerosis
}

\author{
Mohsen Asouri 1,2, Mohammad Ali Sahraian ${ }^{3}$, Morteza Karimpoor ${ }^{1}$, Sadegh Fattahi ${ }^{2}$, Nima Motamed ${ }^{4}$ \\ Rozita Doosti ${ }^{3}$, Galia Amirbozorgi ${ }^{2}$, Shokufeh Sadaghiani ${ }^{3}$, Fereidoun Mahboudi 1, ${ }^{\text {, }}$, Haleh Akhavan-Niaki ${ }^{5,6}$
}

1. Department of Molecular Medicine, Biotechnology Research Center, Pasteur Institute of Iran, Tehran, Iran

2. North Research Center, Pasteur Institute of Iran, Amol, Iran

3. Multiple Sclerosis Research Center; Neuroscience Institute, Tehran University of Medical Sciences, Tehran, Iran

4. Department of Social Medicine, Zanjan University of Medical Sciences, Zanjan, Iran

5. Zoonoses Research Center, North Research Center, Pasteur Institute of Iran, Amol, Iran

6. Department of Genetics, Faculty of Medicine, Babol University of Medical Sciences, Babol, Iran

\section{* Corresponding Author:}

Fereidoun Mahboudi, MD Department of Molecular Medicine, Biotechnology Research Center, Pasteur Institute of Iran, Tehran, Iran Tel: + 982142915000

Fax: +98 2166954324

Email: mahboudi@pasteur.ac.ir

Received: 23 Dec. 2019

Accepted: 02 May. 2020

\section{ABSTRACT}

\section{BACKGROUND}

Multiple sclerosis (MS) is a chronic disease with significant morbidity. A wide spectrum of risk factors has been suggested that triggers the development of MS. Among them, several viral infections have been implicated to play a role in MS pathogenesis.

We aimed to evaluate the relationship between viral diseases, including Epstein-Barr virus (EBV), human herpes virus 6 (HHV-6), cytomegalovirus (CMV), and hepatitis B virus (HBV) and MS in the present case-control study.

\section{METHODS}

About 100 patients with confirmed MS and age- and sex-matched individuals were selected as case and control groups, respectively. The patients were randomly selected from individuals diagnosed by neurologists based on the clinical signs and symptoms and imaging procedures.

\section{RESULTS}

More than 100 patients with MS and patients who were referred for other causes were analyzed for the presence of DNA of EBV, HHV6, CMV, and HBV separately. 9.37\% of the control group had a positive test for the DNA of EBV in a real-time polymerase chain reaction (PCR), while the frequency of positive test result was zero in the case group $(p=0.0012)$. HBV DNA was not detected in both the case and control groups. The prevalence of CMV was 0.88 and zero in the control and case groups, respectively $(p=0.3410)$. For HHV6, $9.73 \%$ of the control group had a positive result, while this test was positive in $5.88 \%$ of the patients with MS $(p=0.2959)$.

\section{CONCLUSION}

We detected a significantly higher number of individuals with DNA of EBV in their blood among the control group compared with the case group. In conclusion, the results suggest a surprisingly adverse association between MS and EBV, and no association was found between the presence of DNA of HBV, CMV, and HHV6 and MS.

KEYWORDS:

Multiple Sclerosis, EBV, HHV6, CMV, HBV.

\section{Please cite this paper as:}

Asouri M, Sahraian MA, Karimpoor M, Fattahi S, Motamed N, Doosti R, Amirbozorgi G, Sadaghiani S, Mahboudi F, Akhavan-Niaki H. Molecular Detection of Epstein-Barr Virus, Human Herpes Virus 6, Cytomegalovirus, and Hepatitis B Virus in Patients with Multiple Sclerosis. Middle East J Dig Dis 2020;12:171-177. doi: 10.34172/mejdd.2020.179.

\section{INTRODUCTION}

Multiple sclerosis (MS), a chronic inflammatory disease of the central nervous system, is characterized by the inflammation and demyelination of white matter and neurodegeneration of the central nervous system (CNS) that leads to significant morbidity and disability. Multifocal demyelinating lesions eventually 
lead to a wide range of clinical symptoms such as cognitive decline, weakened motor skills, behavioral deficits, and vision loss. ${ }^{1,2}$ This chronic immune-mediated disease is considered as the leading cause of non-traumatic related neurologic disability among young people..$^{3-5}$ People with MS may experience a lower life expectancy of up to 7 years based on some previous reports. ${ }^{6}$ It is estimated that more than two million people are suffering from MS. ${ }^{7}$ Based on one report, approximately 2.3 million people were suffering from MS in $2013 .{ }^{8}$ Previous studies in Iran showed that the prevalence and incidence of MS are rapidly increasing, particularly in women. ${ }^{9}$ Overall, it was shown that the prevalence and incidence of MS have critically increased in the last two decades. ${ }^{10}$

Both the environmental and genetic factors are involved in the etiology of MS. Many genes were reported to increase the disease susceptibility, including those who reside in HLA-DRB1*15 loci and alleles in strong linkage with this allele. ${ }^{11}$ There are multiple environmental risk factors for the development of this disease, including sex, age, smoking, vitamin D deficiency, sunshine (UVB), and some pathogens. ${ }^{3}$ Analyzing the role of infectious agents in neurological diseases such as MS has been the goal of many studies. ${ }^{12-21}$ It has been proposed that the activation of autoreactive lymphocytes in the CNS against the infectious agents expressing antigenic molecules, mimicking the glycoproteins and glycolipids, on the surface of the neural cells is conceivably the pathology behind the progression of MS. ${ }^{12,13}$ Several viruses have been associated with the pathogenesis of MS. Among them, Epstein-Barr virus (EBV), human herpes virus 6 (HHV6), cytomegalovirus (CMV), and hepatitis B virus (HBV) have been evaluated for a possible causal association with MS. ${ }^{14-21}$ but inconsistent findings have been provided in different societies.

The aim of this study was to evaluate the relationship between MS and the incidence of infection with EBV, HHV6, CMV, and HBV in a case-control study using real-time PCR as a sensitive molecular method for DNA detection.

\section{MATERIALS AND METHODS}

\section{Studied subjects}

The study participants included 102 patients with MS as the case group and 113 patients as the control group, that were randomly selected from individuals referring to Sina and Shomal Hospitals in Tehran and Amol, Iran. The patients with MS were selected from the individuals whose diseases were positively diagnosed by a neurologist based on McDonald criteria (2010), and confirmed by brain magnetic resonance imaging (MRI). These patients suffered from relapsing-remitting MS (RRMS) or secondary-progressive MS (SPMS). The control group was selected from the patients who were referred to the mentioned hospitals because of other health problems. Both groups were matched according to sex and age. The demographic data, including age, sex, educational level, and the job of the participants were collected. All procedures performed in this study, which involved human participants, were in accordance with the ethical standards of the Pasteur Institute of Iran's Research Committee and with the 1964 Helsinki declaration and its later amendments or comparable ethical standards. This study was approved by the Research Ethics Committee at the Pasteur Institute of Iran (ir.pii. rec.1398.033). Written informed consent was obtained from the participants.

\section{DNA extraction}

DNA was extracted from the blood samples using the QIAamp DNA Mini Kit (Cat. 51104; Qiagen Inc., USA) according to the manufacturer's instructions. Briefly, 200 $\mu \mathrm{L}$ samples were lysed in the presence of lysis buffer and proteinase $\mathrm{K}$ and incubated for $10 \mathrm{~min}$ at $56{ }^{\circ} \mathrm{C}$. Then, ethanol was added and mixed by pulse-vortexing. The mixture was loaded into the QIAamp Mini spin column and centrifuged at $8000 \mathrm{rpm}$ for 60s. The DNA bound to the column was eluted using $60 \mu \mathrm{L}$ elution buffer.

\section{Real-time Polymerase Chain Reaction}

Real-time polymerase chain reaction (PCR) was used to screen the presence of DNA of EBV, CMV, HBV, and HHV6 in the samples on a StepOnePlus ${ }^{\mathrm{TM}}$ real-time PCR system (Applied Biosystems, Life Technologies) in the presence of specific primers and probe (table 1) and HotStarTaq ${ }^{\circledR}$ Plus DNA Polymerase (Qiagen, Hilden, Germany). The cycling conditions consisted of an initial denaturation at $95^{\circ} \mathrm{C}$ for $5 \mathrm{~min}$ followed by 50 cycles, $95^{\circ} \mathrm{C}$ for $15 \mathrm{~s}$, and annealing at $60^{\circ} \mathrm{C}$ for $1 \mathrm{~min}$. Data were collected during each the annealing phase. 
Table 1: Primers used for Viral DNA detection

\begin{tabular}{|c|c|c|c|}
\hline Virus & Viral target & Sequence $5-3$ & Ref \\
\hline \multirow{3}{*}{$\mathrm{CMV}$} & Forward & CAGTCCCGAGACMGTGAGAC & \multirow{3}{*}{10} \\
\hline & Reverse & TGAACATCCCCAGCATCAACG & \\
\hline & Probe & FAM-TGCCACATCTGCTTGCCCGACGC-BHQ1 & \\
\hline \multirow{3}{*}{ HBV } & Forward & GGCCATCAGCGCATGC & \multirow{3}{*}{11} \\
\hline & Reverse & GCTGCGAGCAAAACA & \\
\hline & Probe & FAM-CTCTGCCGATCCATACTGCGGAACTC-BHQ1 & \\
\hline \multirow{3}{*}{ EBV } & Forward & CGGAAGCCCTCTGGACTTC & \multirow{3}{*}{12} \\
\hline & Reverse & CCCTGTTTATCCGATGGAATG & \\
\hline & Probe & FAM-TGTACACGCACGAGAAATGCGCC-BHQ1 & \\
\hline \multirow{3}{*}{ HHV6 } & Forward & TCGAAATAAGCATTAATAGGCACACT & \multirow{3}{*}{13} \\
\hline & Reverse & CGGAGTTAAGGCATTGGTTGA & \\
\hline & Probe & FAM-CCAAGCAGTTCCGTTTCTCTGAGCCA & \\
\hline
\end{tabular}

\section{Statistical analysis}

To compare the continuity of data in the two studied groups, we performed independent $t$ test for data with a normal distribution. When the data did not have the normal distribution, the non-parametric Mann-Whitney test was used to compare the related data in the two groups. To evaluate the association between nominal data, the Chi-square test was used. To remove the confounding effects of other potential mediators, logistic regression analysis with MS as the outcome and viral infections as independent variables were done on the data of patients with MS. The significance level was considered 0.05 for all analyses. All analyses were performed using SPSS software version 21.

\section{RESULTS}

Blood samples were collected from individuals in both case and control groups and analyzed for detection of HBV, EBV, CMV, and HHV-6 DNA. Most of the samples (99 samples) in the case group were obtained from patients with RRMS, whereas three samples were taken from patients with SPMS. The general characteristics of the study populations in the case and control groups are presented in table 2. Individuals with MS had a significantly higher weight than the individuals in the control group $(p<0.001)$. Furthermore, a significantly higher proportion of patients with MS had a positive family history of autoimmune diseases (table 2, $p<0.0001$ ). Most of the patients with MS were female (84 out of 102), showing the higher prevalence of MS among women (Table 3).
HBV DNA was absent in both control and case subjects, and EBV and CMV DNAs were detected only in the control group. 10 individuals (out of 11) in the control group and all individuals in the case group that were positive for HHV-6 were female. Overall, the majority of infected patients were female in both case and control groups (control: 85 women out of 112 [75.8\%]; Case: 84 women out of 102, [82\%]).

Table 4 shows the history of infection with HBV, EBV, CMV, and HHV6 in patients with and without MS based on the presence of viral DNA in their blood. The data show that patients without MS had a significantly higher frequency of EBV infection than patients with MS $(p=0.0012)$. There was no significant difference between the case and control groups for the presence of other viral DNAs.

\section{DISCUSSION}

MS is a chronic inflammatory disease characterized by demyelination of CNS. Several viruses have been suggested to be involved in the pathology of MS, and the most often sited viruses are EBV and HHV- 6 . The present study investigated the prevalence of $\mathrm{HBV}, \mathrm{EBV}$, CMV, and HHV-6 among patients with and without MS. The results of this study showed a significantly higher prevalence of EBV among the control group, while there was no significant association between MS and other viral pathogens. Based on our results, a significantly higher proportion of people without MS had EBV infection compared with people with MS. This finding is not con- 
Table 2: General characteristics of individuals in case and control groups

\begin{tabular}{|c|c|c|c|}
\hline \multirow{2}{*}{ Characteristics } & \multicolumn{2}{|c|}{ Mean \pm SD } & \multirow{2}{*}{$p$-value } \\
\hline & Case & Control & \\
\hline Age (year) & $35.29 \pm 14.66$ & $31.96 \pm 8.25$ & 0.2851 \\
\hline Weight (Kg) & $76.68 \pm 14.57$ & $64.56 \pm 13.28$ & $<0.001$ \\
\hline Height $(\mathrm{cm})$ & $164.29 \pm 14.16$ & $164.43 \pm 8.65$ & 0.7064 \\
\hline SBP (mmHg) & $112.25 \pm 14.36$ & $109.50 \pm 12.21$ & 0.2613 \\
\hline $\mathrm{DBP}(\mathrm{mmHg})$ & $69.00 \pm 8.87$ & $73.22 \pm 9.10$ & 0.0021 \\
\hline \multirow{2}{*}{ Characteristics } & \multicolumn{2}{|c|}{ Proportion (95\% CI) } & \multirow{2}{*}{$p$-value } \\
\hline & Case & Control & \\
\hline A positive history of smoking & $8.00(2.68-13.32)$ & $8.11(3.03-13.19)$ & 0.9770 \\
\hline A positive history of alcohol use & $4.01(0.16-7.85)$ & $4.46(0.64-8.29)$ & 0.8671 \\
\hline A positive family history of Autoimmune disease & $52.75(42.49-63.00)$ & $19.64(12.28-27.00)$ & $<0.0001$ \\
\hline
\end{tabular}

Table 3: Detection of EBV, HBV, CMV, and HHV-6 in the blood samples of control and case groups

\begin{tabular}{lcccccc}
\hline Characteristics & Gender & Number & EBV & HBV & CMV & HHV-6 \\
\hline \multirow{2}{*}{ Control } & Male & 27 & 4 & 0 & 0 & 1 \\
\cline { 2 - 7 } & Female & 85 & 6 & 0 & 1 & 10 \\
\multirow{2}{*}{ Case } & Male & 18 & 0 & 0 & 0 & 0 \\
& Female & 84 & 0 & 0 & 0 & 7 \\
\hline
\end{tabular}

Table 4: The prevalence of viral infection for HBV, EBV, CMV, and HHV6 in case and control groups

\begin{tabular}{lccc}
\hline \multirow{2}{*}{ Viral infection } & \multicolumn{2}{c}{ Proportion (95\% CI) } & \multirow{2}{*}{-value } \\
\cline { 2 - 4 } & Case & Control & 1.000 \\
\hline HBV & $0.00(-)$ & $0.00(-)$ & 0.0012 \\
\hline EBV & $9.73(4.26-15.20)$ & $0.00(-)$ & 0.3410 \\
\hline HHV & $0.88(0-1.97)$ & $5.88(0.32-10.45)$ & 0.2959 \\
\hline
\end{tabular}

sistent with the association between EBV and MS development or exacerbation of MS attacks, as indicated by some previous studies. ${ }^{22}$ Agostini and colleagues reported that DNA viral loads and EBV nuclear antigen-1 (EBNA-1) antibody titers were significantly higher in people with MS than those without it. ${ }^{23}$ Furthermore, Ramroodi and co-workers reported a significant association between the detrimental effects of EBV and MS attacks. ${ }^{24}$ However, Cocuzza and others did not find any association between EBV and MS disease..$^{25}$ In addition to Cocuzza, Franciotta and colleagues did not report any significant relationship between viral infections and MS disease. ${ }^{26}$ They examined the serum and cerebrospinal fluid (CSF) of patients with MS for HSV, varicella-zoster virus (VZV), CMV, EBV, and HHV-6 by PCR amplification method. All serum and CSF samples but one were negative for the existence of viral DNA. On the other hand, in a prospective cohort study, Munger and co-workers showed that anti-EBNA antibodies might be considered as strong markers for the risk of MS development. ${ }^{27}$

We did not find any HBsAg positive individual in our case and control groups. The wide spectrum application of hepatitis B vaccination in Iran could have a critical role in the reduction of hepatitis B prevalence, particularly in young adults. As a result, no detection of HBsAg in our subjects, both MS and control groups, could be expected considering the age of the patients with MS and their age-matched control group. Although some studies have suggested an association between hepatitis $B$ vaccination and the development of MS, a large body of research studies rejects the possibility of any association between them. ${ }^{28-30}$ 
We also evaluated CMV in our case and control groups. While only one positive CMV infection was detected in the control group, no case was detected in those with MS. In a case-control study in northern Iran, Najafi and colleagues found the DNA of CMV in $28 \%$ of patients with MS compared with only $2 \%$ in the control group. ${ }^{31}$ Zivadinov and others reported a relationship between positive titer of CMV antibody and better clinical outcomes of MS, including a later onset of disease development in the lifetime, lower relapse of the disease, and less brain atrophy through MRI evaluation. ${ }^{32}$ In contrast to Zivadinov and others, Salim and co-workers reported that CMV infection could intensify the clinical symptoms in patients with MS ${ }^{32,33}$, but our study suggests no association between a positive CMV infection and MS.

Also, our study did not show any association between HHV6 and MS (table 3, $p=0.2959$ ). Wilborn and colleagues suggested a potential role for HHV6 in the development of MS. ${ }^{34}$ In a systematic review, Pormohammad and others reported a relationship between HHV6 infection and MS. ${ }^{35}$ However, Hon and colleagues did not support a causative role for HHV6 in the development of MS. ${ }^{36}$ Some other studies also did not confirm any association between HHV6 and the development of MS. ${ }^{37,38}$ Our results are in agreement with the latter reports.

Interestingly, the results regarding the relationship between viral infections, including $\mathrm{HBV}, \mathrm{CMV}$, and HHSV6 and the progression to MS are not consistent, and the higher incidence of EBV among the control group suggests an adverse relationship between MS and infection with EBV. While some studies reported a relationship between these viruses and MS, others did not confirm such a relationship. The presence of DNA of HHV6 was also higher in people without MS in comparison with patients with MS, though this was not statistically significant (table 4). This result can be explained by a higher self-care of people with MS for viral infections. Consequently, it may be possible to use more care to prevent viral diseases, as directed by physicians or some self-care measures. On the other hand, due to some disabilities, individuals with MS may play a passive role in the society and thus have lower active contact with other members of the society who are chronic or active carriers of related viruses; and this may result in the lower risk of viral infections. Furthermore, differences in the genotypes of viral infections in different populations may explain the inconsistent results regarding the relationship between these viral infections and the development of MS. Differences in genetic and ethnicity among various populations evaluated by different studies can explain another aspect of this incontinency. $6,39,40$

Like any other research, this study had some limitations. We conducted a case-control study to compare the prevalence of viral infections. In fact, we could not determine whether the infection among MS patients occurred before MS development or during the disease course. Regarding the results from EBV evaluation, we cannot exclude the possibility that EBV could exist in a latent form in any body-compartments, especially in peripheral blood mononuclear cells (PBMCs). As a result, a cause and effect relationship could not be established based on our findings. Although we did a group matching based on some demographic data, including age and sex, many other potential confounding mediators could muddle our findings. On the other hand, the strong associations can be affected by the rare cases of exposure to viruses in our case and control groups. Thus, large cohort populationbased studies or high sample sizes can be more helpful in this context.

\section{CONCLUSIONS}

A significantly higher incidence of viral DNA was detected in the control group in comparison with the case group suggesting a possible adverse effect of EBV on MS. No association was found between the presence of HBV, CMV, and HHV6 DNA and MS disease.

\section{ACKNOWLEDGMENTS}

This work was supported by the Pasteur Institute of Iran. The authors thank the Pasteur Institute of Iran for the financial supports, Patients, and staff of Sina and Shomal Hospitals for their cooperation and assistance in sample collection. The authors also thank Morteza Gholami, Dr. Mehrab Nasiri Kenari, Dr. Mehdi Fakhar, and Masoud Keighobadi for their scientific guidance and language editing. 
ETHICAL APPROVAL

There is nothing to be declared.

\section{CONFLICT OF INTEREST}

The authors declare no conflict of interest related to this work.

\section{REFERENCES}

1. Lassmann H, Brück W, Lucchinetti CF. The immunopathology of multiple sclerosis: an overview. Brain Pathol 2007;17:210-8. doi: 10.1111/j.1750-3639.2007.00064.x.

2. Steinman L. Immunology of relapse and remission in multiple sclerosis. Annu Rev Immunol 2014;32:257-81. doi: 10.1146/annurev-immunol-032713-120227.

3. Ramagopalan SV, Dobson R, Meier UC, Giovannoni G. Multiple sclerosis: risk factors, prodromes, and potential causal pathways. Lancet Neurol 2010;9:727-39. doi: 10.1016/S1474-4422(10)70094-6.

4. Cristiano E, Patrucco L, Rojas J. A systematic review of the epidemiology of multiple sclerosis in South America. Eur J Neurol 2008;15:1273-8. doi: 10.1111/j.14681331.2008.02330.x.

5. Marrie RA, Horwitz RI. Emerging effects of comorbidities on multiple sclerosis. Lancet Neurol 2010;9:820-8. doi: 10.1016/S1474-4422(10)70135-6.

6. Salomon JA, Vos T, Hogan DR, Gagnon M, Naghavi M, Mokdad A, et al. Common values in assessing health outcomes from disease and injury: disability weights measurement study for the Global Burden of Disease Study 2010. Lancet 2012;380:2129-43. doi:10.1016/ s0140-6736(12)61680-8

7. Logroscino G, Piccininni M, Marin B, Nichols E, AbdAllah F, Abdelalim A, et al. Global, regional, and national burden of motor neuron diseases 1990-2016: a systematic analysis for the Global Burden of Disease Study 2016. Lancet Neurol 2018;17:1083-97. doi: 10.1016/S14744422(18)30404-6.

8. Bowne P, Chandraratna D, Angood C, Tremlett H, Baker C, Taylor BV, et al. Atlas of multiple sclerosis 2013: a growing global problem with widespread inequity. Neurology 2014;83:1022-24. doi: 10.1212/ WNL.0000000000000768.

9. Etemadifar M, Sajjadi S, Nasr Z, Firoozeei TS, Abtahi $\mathrm{SH}$, Akbari M, et al. Epidemiology of multiple sclerosis in Iran: a systematic review. Eur Neurol 2013;70:356-63. doi: $10.1159 / 000355140$.

10. Leray E, Moreau T, Fromont A, Edan G. Epidemiology of multiple sclerosis. Rev Neurol 2016;172:3-13. doi:10.1016/j.neurol.2015.10.006.
11. Hollenbach JA, Oksenberg JR. The immunogenetics of multiple sclerosis: a comprehensive review. J Autoimmun 2015;64:13-25. doi: 10.1016/j.jaut.2015.06.010.

12. Fierz W. Multiple sclerosis: an example of pathogenic viral interaction? Virol J 2017;14:42. doi: 10.1186/s12985017-0719-3.

13. Saberi A, Akhondzadeh S, Kazemi S. Infectious agents and different course of multiple sclerosis: a systematic review. Acta Neurol Belg 2018;118:361-77. doi: 10.1007/ s13760-018-0976-y.

14. Guan Y, Jakimovski D, Ramanathan M, Weinstock-Guttman B, Zivadinov R. The role of Epstein-Barr virus in multiple sclerosis: from molecular pathophysiology to in vivo imaging. Neural Regen Res 2019;14:373. doi: 10.4103/1673-5374.245462.

15. Leibovitch EC, Jacobson S. Evidence linking HHV6 with multiple sclerosis: an update. Curr Opin Virol 2014;9:127-33. doi: 10.1016/j.coviro.2014.09.016.

16. Oskari Virtanen J, Jacobson S. Viruses and multiple sclerosis. CNS Neurol Disord Drug Targets 2012;11:528-44. doi: $10.2174 / 187152712801661220$.

17. Voumvourakis KI, Kitsos DK, Tsiodras S, Petrikkos G, Stamboulis E. Human herpesvirus 6 infection as a trigger of multiple sclerosis. Mayo Clin Proc 2010;85:1023-30. doi: $10.4065 / \mathrm{mcp} .2010 .0350$.

18. Khansarinejad B, Soleimanjahi H, Samiee SM, Hamidieh AA, Paryan M, Sanahmadi Y. Quantitation of human cytomegalovirus DNA in plasma using an affordable inhouse qPCR assay. $J$ Virol Methods 2012;183:170-5. doi: 10.1016/j.jviromet.2012.04.010.

19. Welzel TM, Miley WJ, Parks TL, Goedert JJ, Whitby D, Ortiz-Conde BA. Real-time PCR assay for detection and quantification of hepatitis B virus genotypes A to G. J Clin Microbiol 2006;44:3325-33. doi: 10.1128/JCM.00024-06.

20. Kimura H, Morita M, Yabuta Y, Kuzushima K, Kato K, Kojima S, et al. Quantitative analysis of Epstein-Barr virus load by using a real-time PCR Assay. J Clin Microbiol 1999;37:132-6. doi: 10.1128/JCM.37.1.132-136.1999

21. Collot S, Petit B, Bordessoule D, Alain S, Touati M, et al. Real-time PCR for quantification of human herpesvirus 6 DNA from lymph nodes and saliva. $J$ Clin Microbiol 2002;40:2445-51. doi: 10.1128/jcm.40.7.2445-2451.2002.

22. Lossius A, Johansen J, Torkildsen Ø, Vartdal F, Holmøy T. Epstein-Barr virus in systemic lupus erythematosus, rheumatoid arthritis and multiple sclerosis-association and causation. Viruses 2012;4:3701-30. doi: 10.3390/v4123701.

23. Agostini S, Mancuso R, Guerini FR, D'Alfonso S, Agliardi C, Hernis A, et al. HLA alleles modulate EBV viral load in multiple sclerosis. J Transl Med 2018;16:80. doi: 10.1186/s12967-018-1450-6. 
24. Ramroodi N, Niazi AA, Sanadgol N, Ganjali Z, Sarabandi V. Evaluation of reactive Epstein-Barr Virus (EBV) in Iranian patient with different subtypes of multiple sclerosis (MS). Braz J Infect Dis 2013;17:156-63. doi: 10.1016/j.bjid.2012.09.008.

25. Cocuzza CE, Piazza F, Musumeci R, Oggioni D, Andreoni S, Gardinetti M, et al. Quantitative detection of Epstein-Barr virus DNA in cerebrospinal fluid and blood samples of patients with relapsing-remitting multiple sclerosis. PLoS One 2014;9:e94497. doi: 10.1371/journal.pone.0094497.

26. Franciotta D, Bestetti A, Sala S, Perucca P, Jarius S, Price $\mathrm{RW}$, et al. Broad screening for human herpesviridae DNA in multiple sclerosis cerebrospinal fluid and serum. Acta Neurol Belg 2009;109:277-82.

27. Munger K, Levin L, O’Reilly E, Falk K, Ascherio A. AntiEpstein-Barr virus antibodies as serological markers of multiple sclerosis: a prospective study among United States military personnel. Mult Scler 2011;17:1185-93. doi: $10.1177 / 1352458511408991$.

28. Ascherio A, Zhang SM, Hernan MA, Olek MJ, Coplan PM, Brodovicz K, et al. Hepatitis B vaccination and the risk of multiple sclerosis. $N$ Engl J Med 2001;344:32732. doi: 10.1056/NEJM200102013440502.

29. Mikaeloff Y, Caridade G, Rossier M, Suissa S, Tardieu M. Hepatitis B vaccination and the risk of childhoodonset multiple sclerosis. Arch Pediatr Adolesc Med 2007;161:1176-82. doi: 10.1001/archpedi.161.12.1176.

30. Özakbas S, Idiman E, Yulug B, Pakoz B, Bahar H, Gulay Z. Development of multiple sclerosis after vaccination against hepatitis B: a study based on human leucocyte antigen haplotypes. Tissue Antigens 2006;68:235-8. doi: 10.1111/j.1399-0039.2006.00653.x.

31. Najafi S, Ghane M, Poortahmasebi V, Jazayeri SM, Yousefzadeh-Chabok S. Prevalence of cytomegalovirus in patients with multiple sclerosis: a case-control study in northern Iran. Jundishapur J Microbiol 2016;9:e36582. doi: 10.5812/jjm.36582.

32. Zivadinov R, Nasuelli D, Tommasi MA, Serafin M, Bratina A, Ukmar M, et al. Positivity of cytomegalovirus antibodies predicts a better clinical and radiological outcome in multiple sclerosis patients. Neurol Res 2006;28:262-9. doi: 10.1179/016164106X98134.

33. Salim MA, Eftekharian MM, Taheri M, YousefAlikhani M. Determining the IgM and IgG antibody titer against CMV and helicobacter pylori in the serum of multiple sclerosis patients comparing to the control group in Hamadan. Hum Antibodies 2018;26:23-8. doi: 10.3233/HAB-170317.

34. Wilborn F, Schmidt CA, Brinkmann V, Jendroska K, Oettle H, Siegert W. A potential role for human herpesvirus type 6 in nervous system disease. $J$ Neuroimmunol 1994;49:213-4. doi: 10.1016/0165-5728(94)90198-8.
35. Pormohammad A, Azimi T, Falah F, Faghihloo E. Relationship of human herpes virus 6 and multiple sclerosis: A systematic review and meta-analysis. $J$ Cell Physiol 2018;233:2850-62. doi: 10.1002/jcp.26000.

36. Hon GM, Erasmus RT, Matsha T. Low prevalence of human herpesvirus- 6 and varicella zoster virus in blood of multiple sclerosis patients, irrespective of inflammatory status or disease progression. $J$ Clin Neurosci 2014;21:1437-40. doi: 10.1016/j.jocn.2013.10.027.

37. Derfuss $\mathrm{T}$, Hohlfeld R, Meinl E. Intrathecal antibody (IgG) production against human herpesvirus type 6 occurs in about $20 \%$ of multiple sclerosis patients and might be linked to a polyspecific B-cell response. J Neurol 2005;252:968-71. doi: 10.1007/s00415-005-0794-z.

38. Kuusisto H, Hyöty H, Kares S, Kinnunen E, Elovaara I. Human herpes virus 6 and multiple sclerosis: a Finnish twin study. Mult Scler 2008;14:54-8. doi: $10.1177 / 1352458507080063$.

39. Langer-Gould A, Brara SM, Beaber BE, Zhang JL. Incidence of multiple sclerosis in multiple racial and ethnic groups. Neurology 2013;80:1734-9. doi: 10.1212/ WNL.0b013e3182918cc2.

40. Rosati G. The prevalence of multiple sclerosis in the world: an update. Neurol Sci 2001;22:117-39. doi: $10.1007 / \mathrm{s} 100720170011$. 